\title{
Correction to: Incidental hyperkalemia in an infant: Answers
}

\section{Chung-Hsiang Yang ${ }^{1} \cdot$ Ming-Chou Chiang ${ }^{2} \cdot$ Jhao-Jhuang Ding ${ }^{3} \cdot$ Shih-Hua Lin ${ }^{4} \cdot$ Min-Hua Tseng ${ }^{5}$}

Published online: 23 November 2020

(C) IPNA 2020

\section{Correction to: Pediatr Nephrol https://doi.org/10.1007/s00467-020-04729-7}

The authors regret that the name of the author Ming-Chou Chiang was incorrectly rendered as "Min-Chou Chiang". The original article has been corrected.

Publisher's note Springer Nature remains neutral with regard to jurisdictional claims in published maps and institutional affiliations.

The online version of the original article can be found at https://doi.org/ 10.1007/s00467-020-04729-7

Min-Hua Tseng

doc31089@gmail.com

1 Department of Pediatrics, Taoyuan Armed Forces General Hospital, Taoyuan, Taiwan

2 Division of Neonatology, Department of Pediatrics, Chang Gung Memorial Hospital, Taoyuan, Taiwan

3 Department of Pediatrics, National Defense Medical Center, Tri-Service General Hospital, Taipei, Taiwan

4 Division of Nephrology, Department of Medicine, National Defense Medical Center, Tri-Service General Hospital, Taipei, Taiwan

5 Division of Nephrology, Department of Pediatrics, Chang Gung Memorial Hospital, No. 5, Fu-shing ST., Kwei-shan Taoyuan 33305, Taiwan 